\title{
Prenatal exposure to bisphenol A and risk of allergic diseases in early life
}

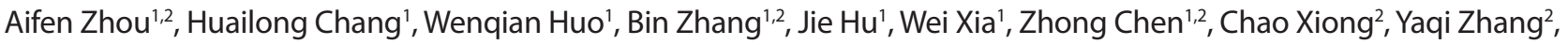 \\ Youjie Wang', Shunqing $\mathrm{Xu}^{1}$ and Yuanyuan $\mathrm{Li}^{1}$
}

BACKGROUND: Prenatal exposure to bisphenol A (BPA) affects immune system and promotes allergy and asthma in mice, but findings in human studies are limited. We investigated whether prenatal exposure to BPA is associated with increased risk of allergic diseases in infants.

METHODS: We measured BPA concentrations in maternal urine samples collected at delivery from 412 women in Wuhan, China. The occurrence of allergic diseases including eczema and wheeze were assessed at age 6 mo through questionnaires. We used logistic regression to evaluate the association between urinary BPA levels and the risk of allergic diseases.

RESULTS: Mothers of infants with allergic diseases had significantly higher urinary BPA levels than those of infants without allergic diseases (median: $2.35 \mathrm{vs} .4 .55 \mu \mathrm{g} / \mathrm{l}, P=0.03$ ). Increased risk of infant allergic diseases was associated with creatinine-adjusted maternal urinary BPA concentrations. And this association was limited to females (odds ratio $(O R)=1.36$; 95\% confidence interval (Cl): 1.10-1.79) rather than males. After stratification by maternal age, the association was only significant in infants of mothers who were younger than $25 \mathrm{y}$ old (OR $=1.90 ; 95 \% \mathrm{Cl}: 1.09-3.29)$.

CONCLUSION: Prenatal exposure to BPA may potentially increase the risk of allergic diseases at very early life in female infants.

$\mathbf{T}$ he prevalence of allergic diseases worldwide is increasing dramatically in both developed and developing countries and children are bearing the greatest burden of the rising trend (1). The potential role of early-life chemical exposures in allergic diseases has gained far less interest in comparison to factors such as inheritance, diet and lifestyle. However, there is increasing evidence that such exposure in the prenatal period may have a significant impact on the development of immune system. For example, it is clear that maternal smoking during pregnancy influences fetal immune development and contributes to increased risk of asthma and allergies in children (2).
Recent attention has been turned to the endocrine disrupting chemicals, to which virtually all people are exposed (3).

Bisphenol A (BPA), a kind of endocrine disrupting chemicals, is used in the manufacture of numerous daily products, and exposures to BPA are ubiquitous around the world (4). BPA can easily cross the placenta (5), which highlights the fetal exposure and potential harmful effects of BPA exposure during this critical period. Prenatal BPA exposure has been suggested to have effects on the immune function in the offspring in experimental studies. T helper 1 and 2 immune responses are augmented by prenatal exposure to BPA (6). Allergic sensitization induced allergic airway inflammation were reported in the offspring prenatally exposed to BPA (7). In addition, perinatal BPA exposure in rats perturbed the naive immune system and led to food intolerance in adulthood (8). However, epidemiological data regarding associations between prenatal BPA exposure and allergic diseases are limited. A cohort study of 398 mother-children pairs reported that high $(2.2 \mu \mathrm{g} / \mathrm{g}$ creatinine) maternal urinary BPA at 16 pregnant weeks were associated with increased odds of children's wheeze before $3 \mathrm{y}$ of age. In Spain, prenatal BPA exposure has been found positively associated with the relative risks of respiratory tract infections and asthma throughout the childhood (9). However, a higher maternal urinary BPA was reported to be inversely associated with wheeze at age $5 \mathrm{y}(10)$.

In light of the accumulating but inconsistent evidence regarding the association between prenatal BPA exposure and allergic diseases, we aimed to investigate whether prenatal exposure to BPA is associated with allergic diseases during the first $6 \mathrm{mo}$ of life in a prospective birth cohort.

\section{METHODS}

\section{Study Population}

This study was conducted at Wuhan Women and Children Medical Care Center, a major maternity hospital in Wuhan, China. Pregnant women were invited to participate in this study at the admission for delivery if they satisfied the following conditions: (i) aged $20 \mathrm{y}$ or older; (ii) have a singleton gestation; (iii) residence in Wuhan during

\footnotetext{
The first two authors contributed equally to this work.

${ }^{1}$ Key Laboratory of Environment and Health, Ministry of Education \& Ministry of Environmental Protection, and State Key Laboratory of Environmental Health, School of Public Health, Tongji Medical College, Huazhong University of Science and Technology, Wuhan, China; ${ }^{2}$ Women and Children Medical and Healthcare Center of Wuhan, Wuhan, China. Correspondence: Yuanyuan Li (liyuanyuan@hust.edu.cn)

Received 23 June 2016; accepted 9 November 2016; advance online publication 5 April 2017. doi:10.1038/pr.2017.20
} 
the recruitment period; and (iv) willingness to be followed up. Six hundred and seventy-nine mother-infant pairs were recruited from November 2012 to April 2014 and all of them were provided with written informed consent at enrollment. Among them, 532 had donated urinary samples and had completed baseline questionnaires. From these, we extracted 423 participants who had completed follow-up questionnaires at 6 mo after birth. After excluding 11 women whose urinary samples showing extremely low or high concentrations of creatinine $(<0.3 \mathrm{~g} / \mathrm{l}$ or $>3 \mathrm{~g} / \mathrm{l})(11)$, a total of 412 participants were included. Participants in this analytic population had similar demographics and other key covariates to the original 679 women (see Supplementary Table $\mathbf{S 1}$ online). Besides, the selection process was shown in Figure 1. The research protocol was approved by the ethics committee of the Tongji Medical College, Huazhong University of Science and Technology.

\section{Exposure Assessment}

We assessed prenatal BPA exposure using maternal urinary BPA concentrations. Maternal urinary samples were collected immediately after the women admitted to the hospital (within $3 \mathrm{~d}$ before delivery) and stored in polypropylene tubes at $-20^{\circ} \mathrm{C}$.

The total BPA (free plus conjugated form) was measured as previously described (12), using ultra performance liquid chromatography-tandem mass spectrometry (UPLC-MS/MS, Waters Acquity UPLC system and Waters TQD triple quadrupole tandem mass spectrometer, Waters Corporation, Maple Street Milford, MA). The limit of detection (LOD) was $0.2 \mu \mathrm{g} / \mathrm{l}$. The regression coefficient of calibration standards with concentrations ranging from 0.1 to $100 \mathrm{ng} / \mathrm{ml}$ was $>0.995$. The samples with concentrations above the calibration range would be further diluted with methanol to reanalyze. Mean recoveries of BPA spiked into sample matrices was $95 \pm 9 \%$. A midpoint calibration standard and methanol blank were injected after every 10 samples to monitor for drift in instrumental response and carry-over from previous injections. Acceptable accuracy was in the range of 85$115 \%$ for midpoint calibration standard. Urine creatinine was analyzed using a creatinine kit (Mindray CREA Kit, Sarcosine Oxidase Method, Shenzhen, China) by an automatic biochemical analyzer (BS-200, Mindray, Shenzhen, China). The creatinine adjusted urinary BPA concentrations were expressed as $\mu \mathrm{g} / \mathrm{g}$ creatinine to control for various urine dilutions.

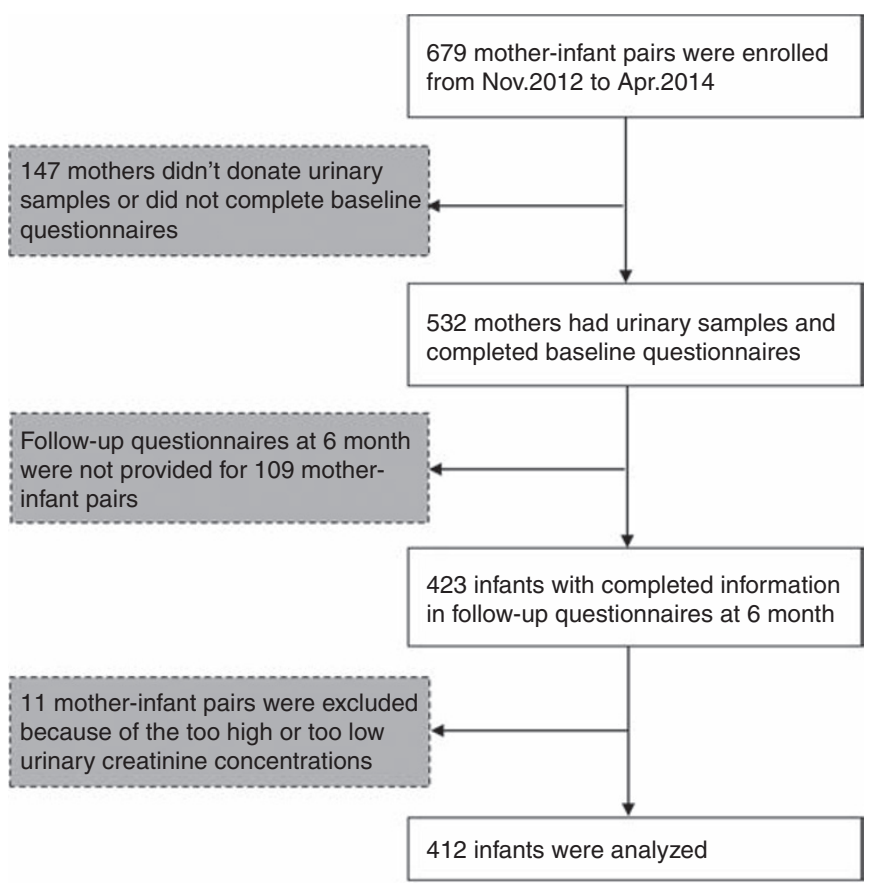

Figure 1. Flow chart representing the process for the original population and selection to analytic population. The gray boxes show the participants excluded from the study.

\section{Outcome Measurement}

We employed trained research assistants to assess the infant's allergies by interviewing the parents using a structured questionnaire. The interviews were conducted at 6 mo after birth over the telephone. Allergic diseases we studied included eczema and wheeze. Eczema was identified by positive answers to both two questions based on the International Study of Asthma and Allergies in Childhood questionnaire: "Has your child had an itchy skin rash, which was coming and going, at any time in the past 6 mo?", "If yes, has this itchy rash affected any of the following places: the fold of elbows, behind the knees, in front of the ankles, under the buttocks, or around the neck, ears, or eyes?", or a positive answer to the single question "Has your child ever had been diagnosed as eczema by a doctor?". Wheeze was identified by a positive answer to the question: "Has your child had wheezing or whistling in the chest in the past $6 \mathrm{mo}$ ".

\section{Covariates}

Baseline information was obtained from standardized face-to-face interviews with the participants conducted by trained nurses within 3 $\mathrm{d}$ before or after delivery. The baseline information included maternal demographic characteristics (date of birth, ethnicity, marital status, and self-reported weight before pregnancy), socioeconomic (education, occupation, and household income), and lifestyle information (alcohol and tobacco exposure). Passive smoking was defined as exposure to secondhand smoke on at least one occasion per week, for at least $30 \mathrm{~min}$ per occasion, either in the home or in public places. Maternal weight at delivery, height, mode of delivery, infants' birth date, gender, and gestational age were all retrieved from medical records. We also collected feeding method and infant tobacco exposure from the follow-up interviews.

\section{Statistical Analysis}

We performed descriptive statistics first. For comparisons between continuous variables, independent $t$-tests or nonparametric tests were used depending on the distributions, and $\chi^{2}$ or Fisher's exact tests were used for categorical variables. When BPA concentrations were below the LOD, we replaced these values with the LOD divided by square root of 2 (13). The distributions of unadjusted and creatinine-adjusted BPA concentrations were tested using KolmogorovSmirnov normality test, and were found to be skewed. So we used log-transformed creatinine-adjusted BPA concentrations (lnBPAcs) to reduce the influence of outlying values. We performed crude and adjusted logistic regression analyses to evaluate the associations of prenatal urinary BPA levels with the risk of developing any one of the symptoms (eczema and wheeze), and $\operatorname{lnBPA}_{\mathrm{CS}}$ was used as a continuous variable. We first performed bivariate analyses to evaluate the association of $\ln B P A_{C S}$ and potential confounders with allergic diseases. Variables considered to be confounders were selected based on either biologic plausibility or if they predicted allergic diseases with a $P$-value $\leq 0.2$ in bivariate analysis. Maternal age and parity were highly correlated $(r>0.50)$ and maternal age was more strongly associated with outcomes than was parity, so we adjusted for maternal age only. In addition, because only one woman raised a pet during pregnancy and only two infants in this study were reported to be exposed to tobacco smoking, maternal pet keeping and infant tobacco exposure were not included.

Model 1 was performed using crude logistic regression analyses to estimate the association between the $\ln \mathrm{BPA}$ and allergic diseases. In model 2, we adjusted only for variables from mothers, including mother's age at delivery, level of education, BMI, passive smoking, and vitamin $\mathrm{D}$ supplementation during pregnancy. In model 3 , we entered variables from both mothers and infants, which included mother's age at delivery, level of education, BMI, passive smoking, and vitamin D supplementation during pregnancy, mode of delivery, gestational weeks, infant gender, body weight at follow-ups, and feeding characteristics.

In the sensitivity analysis, we ran these three models among the 348 full term infants $(\mathrm{GA} \geq 37 \mathrm{wk}$ ), to eliminate the potential effects of preterm birth. The statistical analyses were performed with SAS (version 9.4; SAS Institute, Carry, NC). A $P$-value $<0.05$ was considered statistically significant. 


\section{RESULTS}

Among the 412 participants, there were 38 mothers of infants with allergic diseases and 374 without allergic diseases (Table 1). Compared with those without allergic diseases, mothers of infants with allergic diseases were younger $(27.1$ y old vs. 29 y old), had lower BMI before pregnancy $\left(18.9\right.$ vs. $\left.19.9 \mathrm{~kg} / \mathrm{m}^{2}\right)$, and a higher proportion of vaginal delivery (21.1 vs. $7.8 \%$ ). Mothers of infants with allergic diseases gained slightly more weight during pregnancy than those without allergic diseases $\left(17.8\right.$ vs. $\left.17.0 \mathrm{~kg} / \mathrm{m}^{2}\right)$, had a mildly lower percentage in vitamin D supplement during pregnancy (47.4 vs. $50.0 \%)$, and a mildly higher percentage of who were first time mothers $(89.5$ vs. $80.7 \%$ ). The proportions of mothers whose infants with and without allergic diseases in education levels, occupation status, household income levels, tobacco smoking, and passive smoking during pregnancy were similar. The percentage of female

Table 1. Characteristics of the studied mother-infant pairs

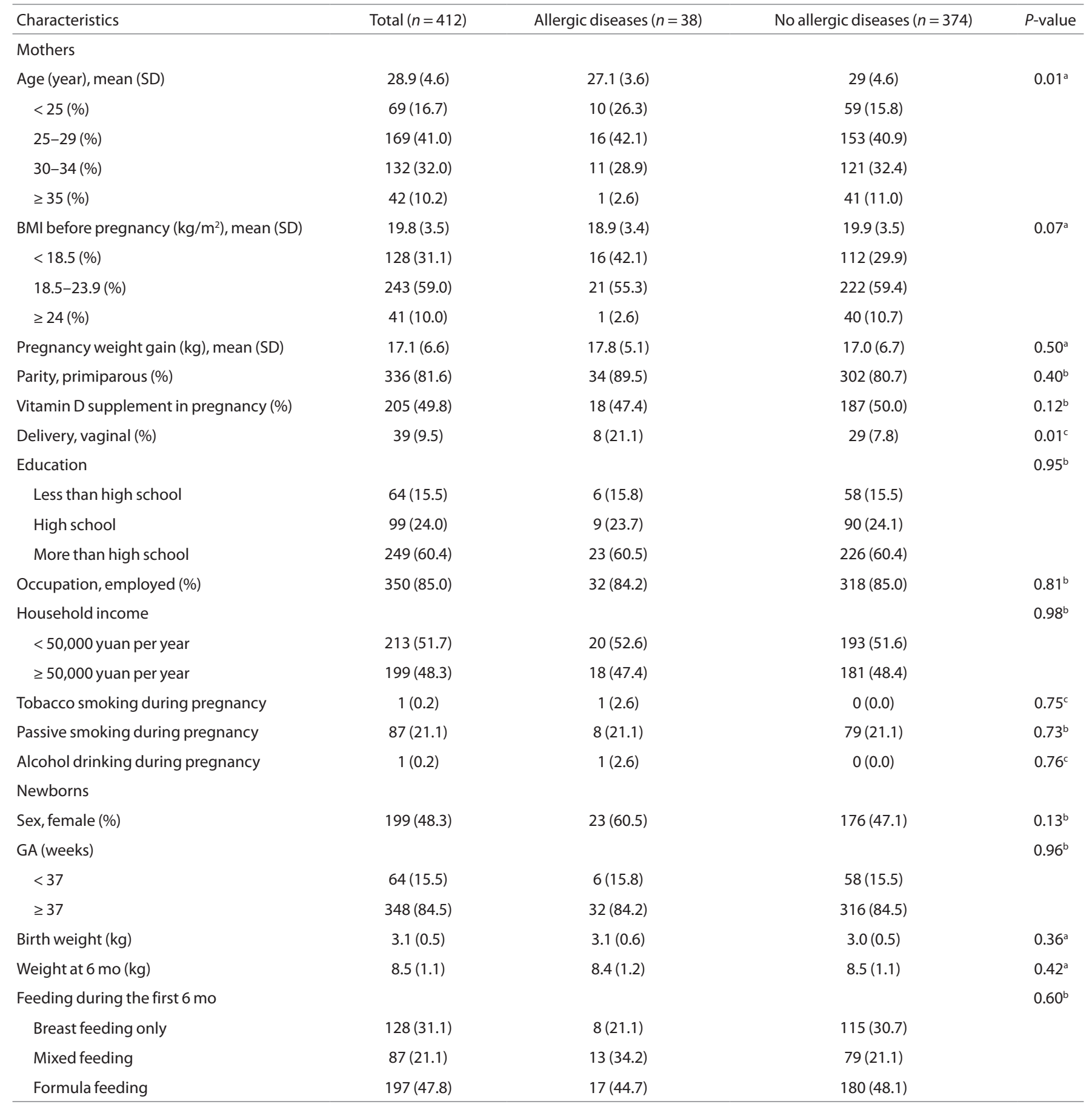

alndependent $t$-test. ${ }^{b} \chi^{2}$-test. 'Fisher's exact test.

$\mathrm{GA}$, gestational age. 


\section{Articles | zhou et al.}

newborns with allergic diseases was higher than those without allergic diseases (60.5 vs. $47.1 \%$ ). The proportions of preterm birth and feeding patterns for the infants with and without allergic diseases were comparable. Besides, the average birth weight $(3.1 \pm 0.6$ vs. $3.0 \pm 0.5 \mathrm{~kg})$ and weight at $6 \mathrm{mo}(8.4 \pm 1.2$ vs. $8.5 \pm 1.1 \mathrm{~kg}$ ) of infants with allergic disease were similar to those without allergic diseases.

BPA was detected in $90 \%$ of the urinary samples in this study. The median of the unadjusted and creatinine-adjusted BPA concentrations in maternal urine were $2.45 \mu \mathrm{g} / \mathrm{l}$ and 4.99 $\mu \mathrm{g} / \mathrm{g}$ creatinine, respectively (Table 2 ). The mothers of infants with allergic diseases had significantly higher unadjusted and creatinine-adjusted BPA levels in comparison with those of

Table 2. Urinary concentrations of BPA in pregnant women

\begin{tabular}{|c|c|c|c|c|c|c|c|}
\hline Concentration & $N$ & AM & GM & Min & 50th & 95th & Max \\
\hline \multicolumn{8}{|l|}{$\begin{array}{l}\text { Unadjusted BPA } \\
(\mu \mathrm{g} / \mathrm{l})\end{array}$} \\
\hline Total & 412 & 8.46 & 2.35 & $<\mathrm{LOD}$ & 2.45 & 35.17 & 201.05 \\
\hline Allergic diseases $^{a}$ & 38 & 10.40 & 4.16 & $<\mathrm{LOD}$ & $4.55^{*}$ & 51.07 & 53.35 \\
\hline No allergic diseases & 374 & 8.27 & 2.22 & $<$ LOD & 2.35 & 34.98 & 201.05 \\
\hline \multicolumn{8}{|l|}{$\begin{array}{l}\text { Creatinine-adjusted } \\
\mathrm{BPA}(\mu \mathrm{g} / \mathrm{g} \text { creatinie) }\end{array}$} \\
\hline Total & 412 & 21.65 & 4.71 & $<$ LOD & 4.99 & 104.64 & 256.18 \\
\hline Allergic diseases ${ }^{\mathrm{a}}$ & 38 & 24.80 & 6.71 & $<$ LOD & $6.69^{+}$ & 113.05 & 248.93 \\
\hline No allergic diseases & 374 & 21.33 & 4.54 & $<$ LOD & 4.80 & 104.56 & 256.18 \\
\hline
\end{tabular}

AM, arithmetic mean; BPA, bisphenol A; GM, geometric mean; LOD, limit of detection; Min, Minimum; Max, Maximum.

aAllergic diseases means cases with at least one of the listed symptoms.

${ }^{*} P=0.03$, compared with the concentration in infants without allergic diseases using

Wilcoxon rank sum test.

${ }^{+} P=0.04$, compared with the concentration in infants without allergic diseases using Wilcoxon rank sum test.

Table 3. Incidences of allergic diseases in infants during the first 6 mo

\begin{tabular}{|c|c|c|c|c|c|c|c|}
\hline \multirow[b]{2}{*}{ Symptoms } & \multicolumn{2}{|c|}{$\begin{array}{c}\text { Total } \\
(n=412)\end{array}$} & \multicolumn{2}{|c|}{$\begin{array}{c}\text { Male } \\
(n=213)\end{array}$} & \multicolumn{2}{|c|}{$\begin{array}{c}\text { Female } \\
(n=199)\end{array}$} & \multirow[b]{2}{*}{$P$-value } \\
\hline & $n$ & $\%$ & $n$ & $\%$ & $n$ & $\%$ & \\
\hline Allergic diseases $^{b}$ & 38 & 9.2 & 15 & 7.0 & 23 & 11.6 & 0.04 \\
\hline Eczema & 26 & 6.3 & 11 & 5.2 & 15 & 7.5 & 0.10 \\
\hline Wheeze & 14 & 3.4 & 5 & 2.3 & 9 & 4.5 & 0.17 \\
\hline
\end{tabular}

aFisher's exact test. ${ }^{b}$ Allergic diseases means cases with at least one of the listed symptoms. infants without allergic diseases (median: 4.55 vs. $2.35 \mu \mathrm{g} / \mathrm{l}, P$ $=0.03$ ).

The frequency of infants with any of the allergic diseases (eczema, wheeze, or both) during the first 6 mo was $9.2 \%$ (Table 3). The numbers of infants with eczema was $26(6.3 \%)$, and wheeze 14 (3.4\%). There was a significant difference in the frequencies of allergic diseases between males and females when taking all the cases into consideration, while no significant differences in the frequencies of eczema- or wheeze-only were found between males and females.

In the crude model or after adjustment for variables from mothers, the $\ln \mathrm{BPA}_{\mathrm{CS}}$ was not associated with the development of allergic disease, except for a positive association between urinary $\ln B$ PAcs and the risk of allergic diseases among female infants in the model adjusted for maternal variables (Table 4). After the variables from infants were included, one unit increase in the $\ln B P A_{C S}$ was associated with an increase of $21 \%$ in the risk of allergic diseases (odds ratio (OR), 1.21; 95\% confidence interval (CI): $1.02-1.47 ; P=0.04)$. We then ran stratified analysis by infant gender. Among female infants, the risk of allergic diseases was significantly associated with $\operatorname{lnBPA}_{\mathrm{CS}}$ when adjusted for confounders from both mothers and infants (OR, 1.36; 95\% CI: $1.10-1.79 ; P=0.03$ ), while no significant association was found among male infants in the crude or any adjusted models.

Among the infants whose mothers were younger than $25 \mathrm{y}$ of age at delivery, ORs for the $\operatorname{lnBPA}_{\mathrm{CS}}$ and allergic diseases increased after incorporation of the confounders from mothers and infants (Table 5). In the crude model, the OR was 1.30 (95\% CI: $0.88-1.92 ; P=0.18$ ). When confounders from mothers and infants were incorporated, the adjusted ORs were 1.51 (95\% CI: 1.03-2.26; $P=0.07)$ and 1.90 (95\% CI: 1.09-3.29; $P=$ 0.02 ), respectively. Among the group of maternal age $\geq 25 \mathrm{y}$, no association between the $\operatorname{lnBPA}_{\mathrm{CS}}$ and risk of allergic diseases was found in any model.

In the sensitivity analysis that only included full term infants, the effect of maternal BPA on the risk of allergic diseases seemed more pronounced among females, given that the associations in the crude and adjusted analyses were all statistically significant (see Supplementary Table S2 online). The ORs for total or male infants were similar with that when included all the preterm and full term infants.

\section{DISCUSSION}

In this cohort study, we evaluated the relationship between prenatal exposure to BPA, estimated by measuring maternal

Table 4. Logistic regression analyses of the associations between maternal bisphenol A (BPA) levels and allergic diseases

\begin{tabular}{|c|c|c|c|c|c|c|}
\hline \multirow[b]{2}{*}{ Model } & \multicolumn{2}{|c|}{ Total $(n=412)$} & \multicolumn{2}{|c|}{ Male $(n=213)$} & \multicolumn{2}{|c|}{ Female $(n=199)$} \\
\hline & $\mathrm{OR}^{\mathrm{a}}\left(95 \% \mathrm{Cl}^{\mathrm{b}}\right)$ & $P$-value & $\mathrm{OR}^{\mathrm{a}}\left(95 \% \mathrm{Cl}^{\mathrm{b}}\right)$ & $P$-value & $\mathrm{OR}^{\mathrm{a}}\left(95 \% \mathrm{Cl}^{\mathrm{b}}\right)$ & $P$-value \\
\hline Unadjusted $^{\mathrm{c}}$ & $1.12(0.95-1.33)$ & 0.17 & $1.07(0.82-1.39)$ & 0.63 & $1.17(0.94-1.46)$ & 0.17 \\
\hline Adjusted $^{d}$ & $1.13(0.93-1.42)$ & 0.12 & $1.06(0.81-1.38)$ & 0.61 & $1.19(0.99-1.61)$ & 0.09 \\
\hline Adjusted+infant variables ${ }^{e}$ & $1.21(1.02-1.47)$ & 0.04 & $1.06(0.81-1.39)$ & 0.67 & $1.36(1.10-1.79)$ & 0.03 \\
\hline
\end{tabular}

${ }^{a} \mathrm{OR}$, odds ratio. ${ }^{\mathrm{b}} \mathrm{Cl}$, confidence interval. ${ }^{\circ} \mathrm{Crude}$ logistic regression model. ${ }^{\mathrm{d} A d j u s t e d}$ for mother's age at delivery, level of education, BMI, passive smoking, and vitamin $\mathrm{D}$

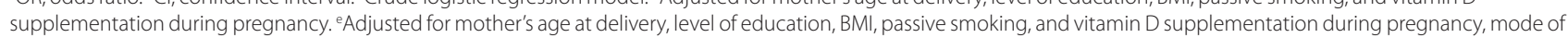
delivery, gestational weeks, infant's gender, body weight at follow-up, and feeding characteristics. In the stratified analysis for male and female infants, infant's gender was excluded from the confounders. 
Table 5. Logistic regression analyses of the associations between maternal bisphenol A (BPA) levels and allergic diseases, stratified by maternal age at delivery

\begin{tabular}{|c|c|c|c|c|}
\hline \multirow[b]{2}{*}{ Model } & \multicolumn{2}{|c|}{$<25$ y $(n=69)$} & \multicolumn{2}{|c|}{$\geq 25$ y $(n=343)$} \\
\hline & $\mathrm{OR}^{\mathrm{a}}\left(95 \% \mathrm{Cl}^{\mathrm{b}}\right)$ & $P$-value & $\mathrm{OR}^{\mathrm{a}}\left(95 \% \mathrm{Cl}^{\mathrm{b}}\right)$ & $P$-value \\
\hline Unadjusted $^{c}$ & $1.30(0.88-1.92)$ & 0.18 & $1.09(0.91-1.33)$ & 0.33 \\
\hline Adjusted $^{d}$ & $1.51(1.03-2.26)$ & 0.07 & $1.10(0.91-1.33)$ & 0.34 \\
\hline $\begin{array}{l}\text { Adjusted+infant } \\
\text { variables }^{\mathrm{e}}\end{array}$ & $1.90(1.09-3.29)$ & 0.02 & $1.12(0.92-1.37)$ & 0.25 \\
\hline
\end{tabular}

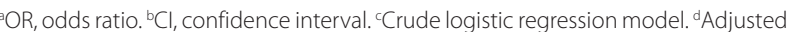
for maternal level of education, BMI, passive smoking, and vitamin D supplementation during pregnancy. ${ }^{e}$ Adjusted for maternal level of education, BMI, passive smoking, and vitamin D supplementation during pregnancy, mode of delivery, gestational weeks, infant's gender, body weight at follow-up, and feeding characteristics.

urinary BPA concentration, and infant's allergic diseases during the first 6 mo of life. We found that creatinine-adjusted urinary BPA concentrations in maternal urine during pregnancy were associated with an increase in the risk of developing allergic diseases as seen in cases with eczema, wheeze, or both, and the associations appeared to be limited to female infants, with little evidence of effects in male infants.

Our results are consistent with two previous cohort studies, where positive associations between maternal urinary BPA levels and wheeze $(9,14)$, chest infections and bronchitis (9) in childhood were found. On the contrary, a cohort study from New York reported that higher urinary BPA concentrations measured during the third trimester of pregnancy were associated with a reduced risk of wheeze at $5 \mathrm{y}$ of age (10). Divergence in the population, exposure assessment and outcome measures from these four studies including this study are summarized in Supplementary Table S3 online. One potential explanation for the different findings might be related to the timing of the outcome measurement. In Spanier et al. (14) study, the maternal urinary BPA was associated with wheeze at 6 mo but not $3 \mathrm{y}$ of age, whereas the New York cohort investigators reported the inverse association at age $5 \mathrm{y}(10)$. In this study, we identified an association between higher maternal BPA levels and allergic diseases during the first $6 \mathrm{mo}$, which is also in the very early life. Another possible explanation might lie in the difference in the timing of the exposure assessment. The vulnerability of fetal developing immune system varies across different periods of pregnancy (15). Spanier et al. (14) assessed BPA exposure during the second trimester, and Gascon et al. (9) used the average of first- and thirdtrimester BPA levels. Donohue et al. (10) study and this study, both assessed BPA exposure during the third trimester.

Some direct mechanistic links by which prenatal exposure to BPA may affect the immune system have been suggested by experimental studies. In murine studies, prenatal BPA exposure led to increased antiovalbumin IgE levels (16), IgG levels, splenic IFN- $\gamma$, and CD4(+)CD44(high)CD62L(low) T lymphocytes activation (8), and the imbalance between $\mathrm{T}$ helper 2 and regulatory T-cell (17). However, because we found a sex difference in the associations between maternal BPA levels and the risk of allergic diseases, these mechanisms may only partly explain the present finding. Another possible explanation may be the endocrine-disrupting properties of BPA. The estrogen has long been suggested to play an active role in allergic diseases (18). BPA can bind to classical and nonclassical estrogen receptors to disrupt estrogen's function (19), and the response of immune cells to estrogen differs between males and females (20). However, some immunoregulatory cells in males and females differ in levels of estrogen receptor, but others do not (21). Thus, further investigation of the potential sex-dependent differences in the effect of prenatal BPA exposure on allergic diseases is needed.

We also found an age specific effect that the associations between maternal BPA levels and the risk of allergic diseases were only apparent in women who were younger than age $25 \mathrm{y}$ at delivery, which is consistent with previous findings that young maternal age is a risk factor for the development of wheeze or asthma $(22,23)$. Higher maternal age has been associated with more pregnancies and siblings, which is associated with lower risk for asthma (24). However, near $82 \%$ of the women in this study were primiparous. The other possible explanations are that higher maternal age may reflect changes in behavior during the pregnancy and in care taking of the child after birth (22).

In comparison with the studies investigating prenatal BPA exposure and allergy in childhood, our populations have similar urinary BPA concentrations to the pregnant women in Gascon et al. (9) and Spanier et al. (14) studies, and are slightly higher than pregnant women from New York City, (10) (see Supplementary Table S3 online). For other published data from pregnant women, urinary BPA concentrations in this study were of similar magnitude as those in France (median 2.4 $\mu \mathrm{g} / \mathrm{l})$ (25), Puerto Rico (median: $2.5 \mu \mathrm{g} / \mathrm{l}$ ) (26), and Cincinnati (median: $2.1 \mu \mathrm{g} / \mathrm{l}$ ) (27), and were a little higher than Greece (median: $1.2 \mu \mathrm{g} / \mathrm{l}$ ) (28) and Korea (median: $1.08 \mu \mathrm{g} / \mathrm{l}$ ) (29). The maternal urinary BPA levels in this study were also comparable to the nonpregnant women (median: $1.73 \mu \mathrm{g} / \mathrm{l}$ ) in Tianjin, China (30), but slightly higher than the pregnant women (median: $0.67 \mu \mathrm{g} / \mathrm{l}$ ) in a study from Nanjing, China (31).

The incidences of infant allergic diseases during the first 6 mo of life in this study were lower than those reported in the previous studies $(9,14)$. In this study, the assessment of the occurrence of allergic diseases was conducted by telephone interviews using questionnaires, which may be under- or over- reported. However, the relative low incidence of allergic diseases is consistent with the reports that the prevalence of asthma is lower in the Chinese population than that in US people (32-34).

A limitation of this study is that the use of one spot maternal urinary BPA concentration may not reflect prenatal BPA exposure accurately, because of the short half-life of BPA and relative low reproducibility of BPA concentrations during pregnancy (35).

Another limitation is the absence of information on maternal history of asthma/allergy. However, the prevalence rate of asthma in Chinese adult is as low as $1.24 \%$ (36), which means there may be five women have asthma in this study. Besides, a previous study has reported the prevalence rate of allergic diseases in Chinese infants aged 0-2.9 y old and 3-5.9 y old were 7.62 and $7.79 \%$, respectively (37), another research represented the prevalence of asthma and eczema in Chinese children aged 


\section{Articles | zhou et al.}

3-16 y old were 3.3 and $5.5 \%$ (38), those rates were comparable to that of our population in this study $(9.22 \%)$. Thus, we believe the associations between maternal BPA concentrations and allergic diseases we found is reliable.

\section{Conclusion}

We found a positive association between maternal urinary BPA concentrations and the risk of infant allergic diseases during the first 6 mo of life, which was apparent only in female infants but not males. While these findings will need further verification in future studies, our data highlighted the concern on the potential health effects of BPA exposure during pregnancy.

\section{SUPPLEMENTARY MATERIAL}

Supplementary material is linked to the online version of the paper at http:// www.nature.com/pr

\section{STATEMENT OF FINANCIAL SUPPORT}

This work was supported by the National Natural Science Foundation of China (81372959, 21437002, 81030051, and 81402649), the National Program on Key Basic Research Project of China (973 Program) (2012CB722401), and the R\&D Special Fund for Public Welfare Industry (Environment) (201309048)

Disclosure: The authors have no potential or perceived conflicts of interest to disclose.

\section{REFERENCES}

1. World Allergy Organization. World Allergy Organization (WAO) white book on allergy, 2011. http://www.worldallergy.org/UserFiles/file/WAOWhite-Book-on-Allergy_web.pdf.

2. Peters JL, Boynton-Jarrett R, Sandel M. Prenatal environmental factors influencing IgE levels, atopy and early asthma. Curr Opin Allergy Clin Immunol 2013;13:187-92.

3. United Nations Environment Programme. State of the Science of Endocrine-Disrupting Chemicals. Geneva: International Programme on Chemical Safety, 2012. http://unep.org/pdf/9789241505031_eng.pdf.

4. Kang JH, Kondo F, Katayama Y. Human exposure to bisphenol A. Toxicology 2006;226:79-89.

5. Balakrishnan B, Henare K, Thorstensen EB, Ponnampalam AP, Mitchell MD. Transfer of bisphenol A across the human placenta. Am J Obstet Gynecol 2010;202:393.e1-7.

6. Yoshino S, Yamaki K, Li X, et al. Prenatal exposure to bisphenol A up-regulates immune responses, including $\mathrm{T}$ helper 1 and $\mathrm{T}$ helper 2 responses, in mice. Immunology 2004;112:489-95.

7. Petzold S, Averbeck M, Simon JC, Lehmann I, Polte T. Lifetime-dependent effects of bisphenol A on asthma development in an experimental mouse model. PLoS One 2014;9:e100468.

8. Menard S, Guzylack-Piriou L, Leveque M, et al. Food intolerance at adulthood after perinatal exposure to the endocrine disruptor bisphenol A. FASEB J 2014;28:4893-900.

9. Gascon M, Casas M, Morales E, et al. Prenatal exposure to bisphenol A and phthalates and childhood respiratory tract infections and allergy. J Allergy Clin Immunol 2015;135:370-8.

10. Donohue KM, Miller RL, Perzanowski MS, et al. Prenatal and postnatal bisphenol A exposure and asthma development among inner-city children. J Allergy Clin Immunol 2013;131:736-42.

11. World Health Organization. Biological monitoring of chemical exposure in the workplace: guidelines, 1996. http://apps.who.int/iris/bitstream/10665/41856/1/WHO_HPR_OCH_96.2.pdf.

12. Huo W, Xia W, Wan Y, et al. Maternal urinary bisphenol A levels and infant low birth weight: a nested case-control study of the Health Baby Cohort in China. Environ Int 2015;85:96-103.

13. Hornung RW, Reed LD. Estimation of average concentration in the presence of nondetectable values. Appl Occup Environ Hyg 1990;5:46-51.

14. Spanier AJ, Kahn RS, Kunselman AR, et al. Prenatal exposure to bisphenol A and child wheeze from birth to 3 years of age. Environ Health Perspect 2012;120:916-20.
15. Rastogi D, Wang C, Mao X, Lendor C, Rothman PB, Miller RL. Antigenspecific immune responses to influenza vaccine in utero. J Clin Invest 2007;117:1637-46.

16. Midoro-Horiuti T, Tiwari R, Watson CS, Goldblum RM. Maternal bisphenol a exposure promotes the development of experimental asthma in mouse pups. Environ Health Perspect 2010;118:273-7.

17. Yan $\mathrm{H}$, Takamoto $\mathrm{M}$, Sugane K. Exposure to Bisphenol A prenatally or in adulthood promotes $\mathrm{T}(\mathrm{H}) 2$ cytokine production associated with reduction of CD4CD25 regulatory T cells. Environ Health Perspect 2008;116:514-9.

18. Bonds RS, Midoro-Horiuti T. Estrogen effects in allergy and asthma. Curr Opin Allergy Clin Immunol 2013;13:92-9.

19. Alonso-Magdalena P, Laribi O, Ropero AB, et al. Low doses of bisphenol A and diethylstilbestrol impair $\mathrm{Ca} 2+$ signals in pancreatic alpha-cells through a nonclassical membrane estrogen receptor within intact islets of Langerhans. Environ Health Perspect 2005;113:969-77.

20. Cunningham M, Gilkeson G. Estrogen receptors in immunity and autoimmunity. Clin Rev Allergy Immunol 2011;40:66-73.

21. Kovats S. Estrogen receptors regulate innate immune cells and signaling pathways. Cell Immunol 2015;294:63-9.

22. Laerum BN, Svanes C, Wentzel-Larsen T, et al. Young maternal age at delivery is associated with asthma in adult offspring. Respir Med 2007:101:1431-8.

23. Marks G, Zinoviev A, Poulos L, Ampon R, Waters A. Asthma in Australian children: findings from growing up in Australia, the longitudinal study of Australian children: Australian Government, Australian Institute of Health and Welfare, 2009. http://www.aihw.gov.au/WorkArea/DownloadAsset. aspx?id=6442453834.

24. McKeever TM, Lewis SA, Smith C, et al. Siblings, multiple births, and the incidence of allergic disease: a birth cohort study using the West Midlands general practice research database. Thorax 2001;56:758-62.

25. Philippat C, Botton J, Calafat AM, Ye X, Charles MA, Slama R; EDEN Study Group. Prenatal exposure to phenols and growth in boys. Epidemiology 2014;25:625-35.

26. Meeker JD, Cantonwine DE, Rivera-González LO, et al. Distribution, variability, and predictors of urinary concentrations of phenols and parabens among pregnant women in Puerto Rico. Environ Sci Technol 2013;47:3439-47.

27. Braun JM, Lanphear BP, Calafat AM, et al. Early-life bisphenol a exposure and child body mass index: a prospective cohort study. Environ Health Perspect 2014;122:1239-45.

28. Myridakis A, Fthenou E, Balaska E, Vakinti M, Kogevinas M, Stephanou EG. Phthalate esters, parabens and bisphenol-A exposure among mothers and their children in Greece (Rhea cohort). Environ Int 2015;83:1-10.

29. Lee BE, Park H, Hong YC, et al. Prenatal bisphenol A and birth outcomes: MOCEH (Mothers and Children's Environmental Health) study. Int J Hyg Environ Health 2014;217:328-34.

30. Zhang T, Sun H, Kannan K. Blood and urinary bisphenol A concentrations in children, adults, and pregnant women from china: partitioning between blood and urine and maternal and fetal cord blood. Environ Sci Technol 2013;47:4686-94.

31. Tang R, Chen MJ, Ding GD, et al. Associations of prenatal exposure to phenols with birth outcomes. Environ Pollut 2013;178:115-20.

32. Forno E, Celedon JC. Asthma and ethnic minorities: socioeconomic status and beyond. Curr Opin Allergy Clin Immunol 2009;9:154-60.

33. Huang J, Huang DM, Xiao XX, et al. [Epidemiological survey of asthma among children aged 0-14 years in 2010 in urban Zhongshan, China]. Zhongguo Dang Dai Er Ke Za Zhi 2015;17:149-54.

34. Yangzong Y, Shi Z, Nafstad P, Håheim LL, Luobu O, Bjertness E. The prevalence of childhood asthma in China: a systematic review. BMC Public Health 2012;12:860.

35. Braun JM, Kalkbrenner AE, Calafat AM, et al. Variability and predictors of urinary bisphenol A concentrations during pregnancy. Environ Health Perspect 2011;119:131-7.

36. Su N, Lin J, Liu G, et al. [An epidemiological survey of current asthma control status in China]. Zhonghua Nei Ke Za Zhi 2014;53:601-6.

37. Cai L, Yu P, Zhang Y, Yang X, Li W, Wang P. Effect of feeding pattern on infant illness in Chinese cities. Public Health Nutr 2016;19:1252-9.

38. Li F, Zhou Y, Li S, et al. Prevalence and risk factors of childhood allergic diseases in eight metropolitan cities in China: a multicenter study. BMC Public Health 2011;11:437. 